\title{
Estado atual da terapia farmacológica para a dependência de álcool: enfoque nas futuras direções para os pesquisadores brasileiros
}

\section{Current state of pharmacological treatment for alcohol dependence: focus on future directions for Brazilian researchers}

\author{
João Mauricio Castaldelli-Maia, Arthur Guerra de Andrade
}

Três em cada quatro pessoas adultas, que moram nas grandes cidades brasileiras, já utilizaram álcool com fins recreativos, segundo o mais recente levantamento do Centro Brasileiro de Informações sobre Drogas Psicotrópicas (CEBRID)ํ. Estima-se que 12,3\% dos moradores dessas cidades sejam dependentes de álcool ${ }^{1}$, o que colocaria essa doença como uma das mais prevalentes na nossa população. Isso torna a dependência de álcool um dos principais problemas de saúde pública da nossa população. Nem mesmo a dependência de tabaco, que atingiu uma prevalência estimada de $10,1 \%$ no mesmo levantamento ${ }^{1}$, conseguiu atingir um nível tão alto como o álcool, apesar de se tratar de um problema igualmente importante e de difícil resolução.

Um grande obstáculo para controle da grande prevalência de dependentes de álcool é a dificuldade no tratamento dos mesmos². Essa é uma situação mundial, o que deixa claro a necessidade do aprimoramento da terapêutica do alcoolismo. O tratamento da dependência de álcool é multidisciplinar, no qual o tratamento farmacológico é apenas uma parte importante. Outros componentes também importantes são as terapias psicológicas (como entrevista motivacional e a terapia cognitivo-comportamental) e o suporte social.

No contexto da terapia farmacológica, a pesquisa da eficácia de medicamentos que já estão em uso, bem como o desenvolvimento de novos medicamentos que possam ser eficazes nesse tratamento, são especialmente importantes². Dentro disso, é importante a pesquisa que visa à replicação dos ensaios clínicos nas diversas populações para a comparação dos resultados e tamanho de efeito. Recentemente, a equipe de desenvolvimento de medicamentos do National Institute on Alcohol Abuse and Alcoholism (NIAAA) dos Estados Unidos, a maior organização de estudo no campo dos problemas relacionados ao uso do álcool, identificou três diretrizes ${ }^{3}$ que devem guiar as ações da entidade nesse campo em longo prazo: (1) tornar o processo de desenvolvimento de drogas mais eficientes; (2) identificar medicamentos mais eficazes, personalizar abordagens de tratamento, ou ambos, e (3) facilitar a implementação e adaptação de medicamentos em ambientes do mundo real de tratamento 3 .

Em cuidadoso estudo de revisão de literatura, Almeida e do Souto ${ }^{2}$ analisaram toda a contribuição de grupos de pesquisa brasileiros na avaliação de medicações para o tratamento da dependência de álcool. Existem poucos grupos do nosso país que se detiveram na pesquisa desse campo. Alguns ensaios clínicos randomizados, estudos transversais e um relato de caso, realizados com população local, além de uma revisão, foram encontrados. Esses trabalhos foram publicados por alguns grupos de renome em pesquisa como o Grupo Interdisciplinar de Estudos de Álcool e Drogas (GREA) do Instituto de Psiquiatria da Universidade de São Paulo (USP), a Unidade de Pesquisa em Álcool e Drogas (UNIAD), entidade liderada por pesquisadores do Departamento de Psiquiatria da Universidade Federal da São Paulo (UNIFESP), o Programa de Estudos e Assistência ao Uso Indevido de Drogas (PROJAD) do Instituto de Psiquiatria da Universidade Federal do Rio de Janeiro (UFRJ), e o Laboratório de Ciências Cognitivas e Neuropsicofarmacologia da Universidade Federal do Espírito Santo (UFES).

O Food and Drug Administration (FDA), órgão governamental dos Estados Unidos da América responsável pelo controle dos alimentos (tanto humano como animal), suplementos alimentares, medicamentos (humano e animal), cosméticos, equipamentos médicos, materiais biológicos e produtos derivados do sangue humano, aprova atualmente três medicações para o tratamento da dependência de álcool ${ }^{4}$. São elas: dissulfiram, naltrexona e acamprosato. O topiramato, uma medicação usada para tratar epilepsia e enxaqueca, tem a sua eficácia cada vez mais comprovada para o tratamento da dependência do álcool por diversos estudos, mas o FDA ainda não aprovou a sua utilização. Além desses quatro medicamentos já consagrados no tratamento desses pacientes, existem outros fármacos promissores que estão sendo estudados atualmente ${ }^{4}$. Os estudos de pesquisadores brasileiros ${ }^{2}$ se

Disciplinas de Psiquiatria e Psicologia Médica da Faculdade de Medicina do ABC (FMABC) - Santo André (SP), Brasil; Departamento de Psiquiatria da Faculdade de Medicina da Universidade de São Paulo (USP) - São Paulo (SP), Brasil.

E-mail: jmcmaia2@gmail.com 
concentram nas três medicações aprovadas pelo FDA, além do topiramato e da gabapentina. Apesar de serem utilizadas para tratar a mesma doença, o efeito dessas medicações no organismo é diferenciado.

O dissulfiram, a primeira droga aprovada para o tratamento da dependência do álcool, é, ainda, um dos agentes mais utilizados ${ }^{4}$. Ele produz uma interação aversiva com o álcool, por interferir na metabolização do mesmo. Durante o seu metabolismo, o álcool é inicialmente convertido em acetaldeído, que, em seguida, é metabolizado pela enzima aldeído desidrogenase. O dissulfiram inibe esta última reação, levando a um acúmulo de acetaldeído, o que resulta em efeitos desagradáveis, como náusea, vômito, palpitações e dores de cabeça quando o indivíduo faz uso de bebidas alcoólicas.

A naltrexona é um antagonista opioide ${ }^{4}$ que age nos efeitos prazerosos do álcool. A naltrexona bloqueia os efeitos do álcool na atividade opioide endógena. Quando ingerido, o álcool estimula indiretamente a atividade opioide endógena ao promover a liberação dos peptídeos endógenos (encefalinas e beta-endorfinas) na fenda sináptica.

O acamprosato foi aprovado para utilização no tratamento do alcoolismo, nos Estados Unidos, em 2004, seguindo de um uso extensivo em muitos outros países do mundo ${ }^{4}$. Infelizmente, esse medicamento não está disponível no Brasil no momento. Atribui-se o efeito terapêutico dessa medicação nos dependentes de álcool ao fato do mesmo equilibrar as vias excitatórias e inibitórias alteradas pelo consumo de álcool crônico ${ }^{4}$. Age principalmente em uma subclasse dos receptores glutamatérgicos. Um dos pontos fortes do acamprosato é o seu perfil favorável de efeitos colaterais

O topiramato é um anticonvulsivante. Sua eficácia está baseada na hipótese de que o mesmo teria efeitos benéficos sobre a dependência ao facilitar o funcionamento do neurotransmissor $\gamma$-aminobutírico (GABA) e sendo um antagonista glutamatérgico ${ }^{4}$. Essa medicação pode ser particularmente útil para tratamento de depedentes de álcool com síndrome de abstinência alcoólica. O aumento da dose ingerida deve ser feito com cautela, para minimizar efeitos colaterais. O topiramato é provavelmente o novo tratamento mais promissor da dependência de álcool ${ }^{4}$. No entanto, mais pesquisas são necessárias para determinar a dose ideal e o tempo adequado de tratamento 5 .

Outros medicamentos que agem nos sistemas dos neurotransmissores GABA e glutamato são promissores no tratamento para retirada do álcool aguda e prolongada e para a prevenção de recaída ${ }^{4}$. Um exemplo deles é a gabapentina, um anticonvulsivante de ação gabaérgica, que se mostra especialmente promissor para tratar abstinência de álcool e para melhorar as taxas de abstinência no início do tratamento nos dependentes com alto índice de síndrome de abstinência alcoólica ou com comorbidade com insônia ${ }^{3}$.

Recente revisão $0^{5}$ aponta duas medicações, além do topiramato, como promissoras para serem incorporadas ao tratamento da dependência de álcool, além das três já aprovadas pelo FDA: baclofeno e ondansetron. Não encontramos estudos com essas medicações na revisão de Almeida e do Souto 2 , o que indica que elas ainda não foram estudadas por pesquisadores brasileiros e poderiam ser alvo de futuras linhas de pesquisa nacionais, a nosso ver.

Existem indícios de que o tratamento com o baclofeno ${ }^{4}$, que é um agonista do receptor GABA-B (utilizado para espasticidade muscular), possa ser eficaz para reduzir as propriedades de reforço e motivação do álcool, além de outros sintomas. A hipótese que explicaria os efeitos do baclofeno em dependentes se baseia na ação desse fármaco nos receptores GABA-B, o que neutralizaria a ação dopaminérgica do álcool em áreas do sistema de recompensa.

$\mathrm{O}$ ondansetron ${ }^{4}$ (antagonista de receptor serotoninérgico tipo 3 - 5HT-3, já aprovado para tratamento de náusea) mostra alguma eficácia para reduzir o beber pesado em pacientes com dependência de álcool de início precoce e com histórico familiar de dependência de álcool importante.

Futuras linhas de pesquisa devem procurar medicamentos para outros transtornos ou disfunções relacionadas ao uso de álcool que não estejam compreendidas no diagnóstico de depedendência ${ }^{4}$. Vale lembrar, que as propostas para o próximo manual de diagnósticos da American Psychiatry Association, que atingirá a sua quinta edição (Diagnostic and Statstical Manual of Mental Disorders, Fifth edition - DSM-V), em 2014, deverá agrupar todos os sintomas de dependência e abuso (com exceção de um sintoma de abuso) em um mesmo diagnóstico (alcohol use disorder - sem tradução para o português, ainda). Além disso, outras linhas poderiam explorar o uso desses medicamentos nos diversos ambientes de tratamento para os dependentes. Para otimizar os resultados do tratamento de medicamentos ${ }^{4}$, os profissionais precisam avaliar o nível apropriado de orientação para os pacientes e os métodos adequados para melhorar a adesão à medicação ${ }^{4}$ o que é uma dificuldade em quase todas as áreas da psiquiatria.

Em suma, a pesquisa no campo do desenvolvimento de medicações para o tratamento de dependentes de álcool é essencial, mas muito pouco desenvolvida no Brasil. Existem poucos estudos realizados em apenas uma única região do país. Em nível nacional, esforços devem ser realizados para incentivar um maior número de estudos nos grupos já existentes e o desenvolvimento de novos grupos de pesquisa fora da região sudeste. Ensaios clínicos randomizados são os estudos de maior qualidade e devem ser a grande meta de todo o pesquisador que se aventure nesse campo. Esse tipo de estudo tenta controlar todas as possíveis variáveis de confusão para poder analisar a eficácia de um tratamento, em comparação com o placebo, ou um tratamento já comprovadamente eficaz. Ondansetron e baclofeno ainda não foram testados em amostras brasileiras, e podem ser terapêuticas interessantes para futuros estudos dos nossos pesquisadores. Além disso, pesquisa com grupos de pacientes com uso problemático de álcool que não estejam incluídos no diagnóstico de dependência e com a otimização do tratamento (orientação individualizada e mecanismos de melhora da adesão) também se mostram como áreas promissoras. 


\section{Referências}

1. Fonseca AM, Galduroz JCF, Noto AR, Carlini ELA. Comparison between two household surveys on psychotropic drug use in Brazil: 2001 and 2004 . Ciênc Saúde Coletiva 2010;15(3):663-70.

2. Almeida UA, do Souto RP. Contribuição de grupos de pesquisa brasileiros na avaliação de fármacos para o tratamento da dependência de álcool. Arq Bras Ciênc Saúde 2012;37(3):162-7.

3. Litten RZ, Egli M, Heilig M, Cui C, Fertig JB, Ryan ML, et al. Medications development to treat alcohol dependence: a vision for the next decade. Addict Biol 2012;17(3):513-27.

4. O'Malley SS, O'Connor PG. Medications for unhealthy alcohol use: across the spectrum. Alcohol Res Health 2011;33(4):300-12.

5. Edwards SM, Kenna GA, Swift RM, Leggio L. Current and promising pharmacotherapies, and novel research target areas in the treatment of alcohol dependence: a review. Curr Pharm Des 2011;17(14):1323-32. 